\title{
Acute hand and wrist injuries in experienced rock climbers
}

\author{
A J Logan, N Makwana, G Mason, J Dias
}

Br J Sports Med 2004;38:545-548. doi: 10.1136/bjsm.2003.003558

See end of article for authors' affiliations ....................

Correspondence to: Mr Logan, Orthopaedics, Wrexham Maelor Hospital, Croesnewydd Rd, Wrexham LL13 7TD, Wales, UK; andrew. logan@ntlworld.com

Accepted 11 August 2003

\begin{abstract}
Background: The sport of rock climbing has its own spectrum of injuries, almost half of which involve the wrist and hand.

Objective: To examine the incidence of acute wrist and hand injuries in 545 members of The Climbers' Club of Great Britain.

Method: A total of 1100 questionnaires were sent to current members of The Climbers' Club of Great Britain for them to detail any hand and wrist injuries sustained to date. In decade years, the climbing grades and time spent climbing at each grade were determined. From these results a total and historic climbing intensity score for each climber could be calculated.

Results: Half of the questionnaires were returned complete. The respondents were almost entirely male. There were 235 wrist and hand injuries in 155 climbers $(28 \%)$. The climbing intensity scores were significantly higher in the injury group than in those who had not suffered a wrist or hand injury $(p<0.05)$. Finger tendon injuries were the most common injury, followed by abrasions/lacerations and fractures.

Discussion: The most common injuries found in rock climbing involve the wrist and hand. The predominant injury to the hand involves the finger tendons or pulleys. The greater the climbing intensity calculated over a climber's career, the greater the likelihood of sustaining these injuries.
\end{abstract}

$\mathrm{T}$ he sport of rock climbing is increasing in popularity in the United Kingdom. As with any competitive or recreational sport, climbing has a spectrum of associated injuries. A series of repetitive high torque movements of the upper limbs are needed to ascend a wall or rock face. These movements subject the hand and wrist to large forces, potentially resulting in ligament and tendon sprains or rupture. Direct injury to climbers from falls and rockfalls are also well recognised. Almost half of all injuries sustained in the sport of rock climbing involve the wrist and hand. ${ }^{12}$ This study examines the incidence of acute wrist and hand injuries sustained by 545 members of The Climbers' Club of Great Britain as recorded in questionnaires about their climbing careers to date. Once climbers join the Club they usually remain members for life. The current membership is predominantly male (about $90 \%$ ) as the admission of women is relatively recent. The data were acquired as part of a large study involving the incidence of Dupuytren's contracture in climbers. Data were collected on hand and wrist injuries as part of the survey, and it is these results that are reported here.

\section{METHODS}

A questionnaire was sent to 1100 members of The Climbers' Club of Great Britain (fig 1). The members were asked to itemise the type and severity of any past wrist or hand injury. Only injuries sustained while climbing were included. These included fractures, dislocations, crush injuries, burns, cuts, abrasions, and tendon damage. Details of each member's rock climbing history were also recorded (table 1). For each climber, the amount of climbing per year and the average technical grade at which they climbed during each decade of their climbing career to date was noted. The grading scores given were converted into the English adjusted technical grade. Each adjusted grade was scored from 3 (M) to 19 (E6) (table 2). From these details, the score assigned to each adjusted technical grade (3-19) was multiplied by the average number of days a year that the climber had spent climbing at that grade for each decade. The same was calculated for every decade that each climber had climbed for his or her whole climbing career to date. All technical grade scores for each climber were added together to give a total climbing intensity score for that climber (example 1). This single numerical value for each climber represented the lifetime exposure to rock climbing. From this information, the pattern and incidence of wrist and hand injuries could be related to the intensity of climbing. Statistical significance was calculated using the $\mathrm{Z}$ test for the equality between the mean climbing intensity scores of the injury and non-injury groups. A nominal value of $\mathrm{p}<0.05$ was used to establish significance.

\section{RESULTS}

A total of 562 questionnaires were returned (51\%), 17 of which were incomplete and omitted from the study. Therefore data were complete for 545 cases (50\%); 496 responders were male and 49 female $(9 \%)$. The mean age of the climbers at the time of questionnaire completion was 50 years (range 23-93), and this confirmed the "membership for life" scenario. There were 155 climbers (28\%) with 235 wrist and hand injuries. The mean age at the time of injury was 33 years (13-63). The mean number of years between injury and questionnaire completion was $19(<1-55)$. Figure 2 illustrates the percentage of climbers injured for each age group. The mean climbing intensity score in the injury group was 3281 compared with 1877 in the non-injury group. This was significant $(\mathrm{p}=0.01)$. Table 3 shows the types and frequency of wrist and hand injuries sustained. Finger tendon injuries were the most common $133 \%$ of the total number of injuries) which included non-specified finger tendon injuries (25\%) and those diagnosed with specific A2 pulley ruptures $(8 \%)$. Lacerations to the wrist, hand, and fingers were common, at $15 \%$ of all injuries, occurring from contact with the rock face either during climbing itself or from falls or rockfalls. One fifth of hand injuries were fractures. These included wrist (12\%) and phalangeal/ metacarpal bone fractures $(7 \%)$. These were usually a result of falls or rockfalls. Phalangeal and thumb dislocations were common, accounting for $13 \%$ of the total number of hand injuries. Rope burn was another noteworthy injury pattern 
QUESTIONNAIRE TO MEMBERS OF THE CLIMBERS' CLUB ON DUPUYTRENS CONTRACTURE

see Newsletter for full details

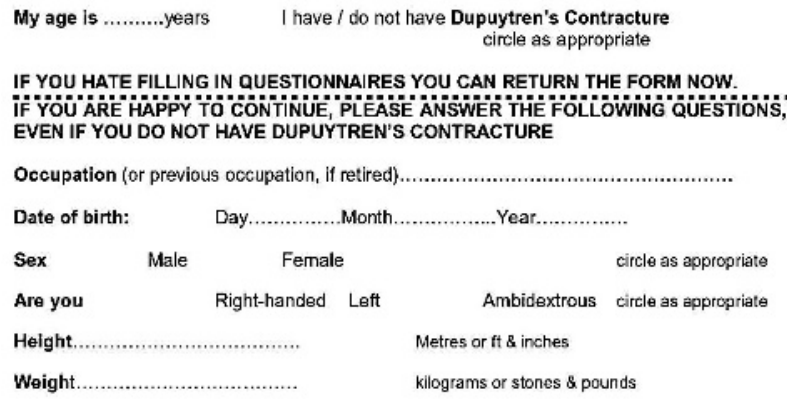

Please fill in the following table about your rock climbing history. Approximate numbers will do. We are trying to identify the intensity of past and current activity.

\begin{tabular}{|l|l|l}
\hline Age (years) & $\begin{array}{c}\text { Days per year } \\
\text { of climbing }\end{array}$ & $\begin{array}{l}\text { Average grade } \\
\text { of climbing }\end{array}$ \\
\hline example & 25 & VS \\
\hline-20 & & \\
\hline $21-30$ & & \\
\hline $31-40$ & & \\
\hline $41-50$ & & \\
\hline $51-60$ & & \\
\hline $61-70$ & & \\
$71-80$ & & \\
\hline $81-90$ & & \\
\hline $90+$ & & \\
\hline
\end{tabular}

Hand and wrist injuries

Please indicate (approximately will do) the type of any significant injury to hands or wrists (i.e. fracture, dislocation, crush, burn, scald, severe cut or abrasion etc.), its cause (i.e. climbing work, domestic accident etc.), and severity (graded from extreme (crush or scald of whole hand). very severe (limited to part of the hand), severe (dislocation or fracture of a bone or (wo) to moderate (severe cut or abrasion)).

age

type

cause

severity

Figure 1 Wrist and hand injury section of the questionnaire.

found in this study (9\%), caused almost exclusively from saving a falling colleague. Other less common injuries included soft tissue sprains to the wrist $(5 \%)$, crush injuries to the hand $(4 \%)$, frostbite $(1 \%)$, and finger amputation (1\%). The mean age of the climber and mean climbing intensity scores showed no significant difference between each injury group.

\section{DISCUSSION}

Injuries in rock climbers are common. During their climbing career, $83 \%^{1}$ to $89 \%^{3}$ of climbers reported a history of least one acute injury symptomatic for 10 days or more. These acute injuries are mainly the result of a sudden tendon/

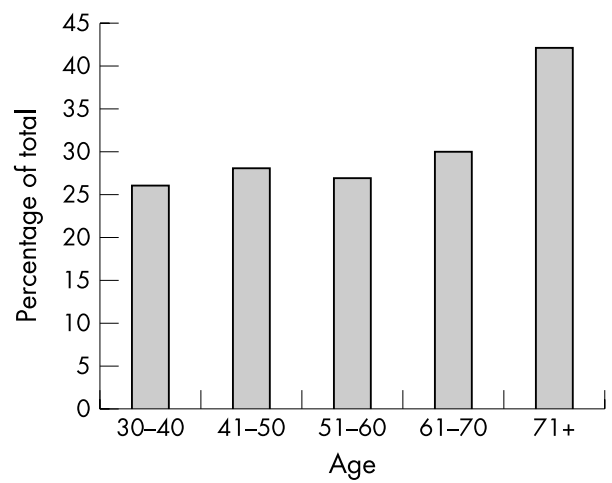

Figure 2 Percentage of climbers with hand injuries per age group.

\begin{tabular}{lll} 
Table 1 & Volume and grade of climbing \\
\hline Age (years) & $\begin{array}{l}\text { Mean No } \\
\text { climbing days } \\
\text { a year }\end{array}$ & $\begin{array}{l}\text { Average grade } \\
\text { of climbing }\end{array}$ \\
\hline Example & 25 & VS \\
-20 & & \\
$21-30$ & & \\
$31-40$ & \\
$41-50$ & \\
$51-60$ & \\
$61-70$ & \\
$71-80$ & \\
$81-90$ & \\
$90+$ & \\
\hline
\end{tabular}

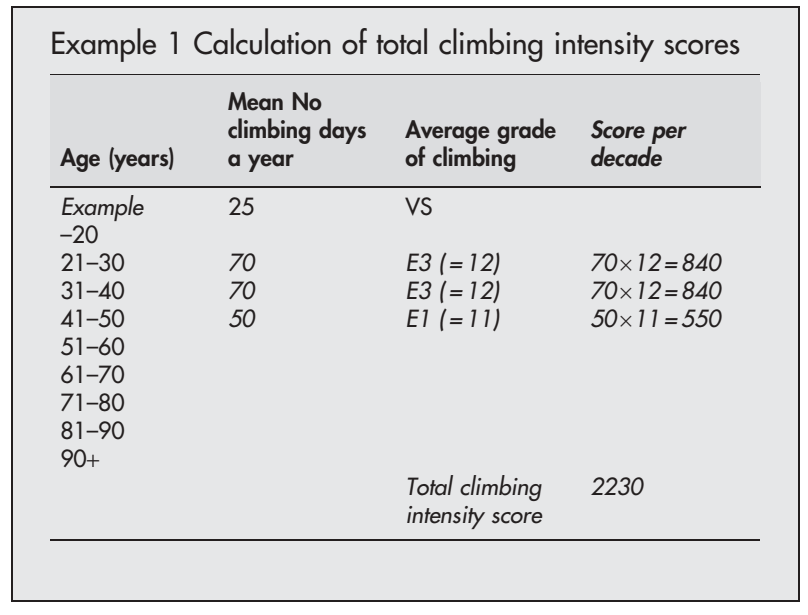

ligament strain or a fall, with almost half occurring while training ${ }^{1}$ and two thirds during the ascent. ${ }^{4}$ Overuse injuries are also common and occur in more than $40 \%$ of indoor rock climbers. ${ }^{5}{ }^{6}$ Hand and wrist injuries account for almost half of all acute climbing injuries. ${ }^{1237}$

This study looked at hand and wrist involvement alone with a total of 235 injuries in 155 climbers. From a total of 545 replies, $28 \%$ of climbers questioned had sustained a hand or wrist injury in their lifetime. In comparison, a survey of $13 \%$ of the Danish population found that, per year, $0.037 \%$ suffered a hand or wrist injury severe enough to attend an

\begin{tabular}{ll}
$\begin{array}{l}\text { Table } 2 \text { Multiple assigned to each adjusted } \\
\text { technical grade }\end{array}$ \\
\hline $\begin{array}{l}\text { Adjusted technical } \\
\text { climbing grade }\end{array}$ \\
\hline M (moderate) & $\begin{array}{l}\text { Multiple assigned to } \\
\text { each grade }\end{array}$ \\
D (difficult) & 3 \\
VD (very difficult) & 4 \\
HVD (hard very difficult) & 5 \\
S (severe) & 6 \\
HS (hard severe) & 7 \\
VS (very severe) & 8 \\
HVS (hard very severe) & 9 \\
E1 (Extreme 1) & 10 \\
E2 (Extreme 2) & 11 \\
E3 Etc. & 12 \\
E4 & 13 \\
E5 & 14 \\
E6 & 15 \\
ET & 16 \\
E8 & 17 \\
E9 & 18 \\
\hline & 19 \\
&
\end{tabular}




\begin{tabular}{|c|c|c|c|}
\hline Injury & $\begin{array}{l}\text { Frequency } \\
\text { (\% of total } \\
\text { injuries) }\end{array}$ & $\begin{array}{l}\text { Mean } \\
\text { climber age } \\
\text { (years) }\end{array}$ & $\begin{array}{l}\text { Mean } \\
\text { intensity } \\
\text { score }\end{array}$ \\
\hline Finger tendon injury & 25 & 57 & 2296 \\
\hline Laceration/abrasion & 15 & 56 & 1781 \\
\hline Finger/thumb dislocation & 13 & 58 & 2070 \\
\hline Wrist fracture & 12 & 59 & 1820 \\
\hline Rope burns & 9 & 56 & 1997 \\
\hline Finger pulley injury & 8 & 56 & 1789 \\
\hline $\begin{array}{l}\text { Finger/metacarpal } \\
\text { fracture }\end{array}$ & 7 & 54 & 2551 \\
\hline Soft tissue sprain wrist & 5 & 59 & 2575 \\
\hline Crush injury & 4 & 55 & 2043 \\
\hline Frostbite & 1 & 56 & 1233 \\
\hline Finger amputation & 1 & 60 & 3123 \\
\hline
\end{tabular}

accident and emergency department. ${ }^{8}$ One third of these were related to leisure accidents. The mean climber age in this study was 50 years. If this population did not climb, then, at the Danish rate of incidence, only approximately $2 \%(50 \times$ 0.037 ) should have suffered a hand or wrist injury by the age of 50. Based on these figures, it might be concluded that members of the Climbers' Club, who are active climbers, suffered more than 14 times more hand injuries than the general population over an equivalent time period.

The incidence of hand and wrist injuries of $28 \%$ in this study is similar to that found by Maitland ${ }^{5}$ who surveyed climbers who were members of, or currently climbing at, a pursuits centre climbing wall. However, the mailing part of the survey gave a low response rate of only $26 \%$. Most other studies have found a much higher incidence of wrist and hand injuries. ${ }^{139}$

These previous studies on the incidence of climbing injuries have questioned climbers at climbing competitions ${ }^{6}{ }^{10}$ and climbing symposia. ${ }^{1}$ Competitions usually involve elite climbers who are younger and within a narrow age range. This group may not be representative of a typical club climber. The Climbers' Club of Great Britain is a membersonly club founded in 1898. To obtain membership, the climber must climb with existing members for about one year and then formally apply for membership with references from members. They climb at different grades and also differ in the number of weeks spent climbing in their climbing career to date. This study therefore represented dedicated and experienced climbers who are likely to climb regularly during their active climbing career.

The mean climbing intensity scoring, as applied in this study to Climbers' Club members, is likely to be less than the scoring for elite climbers competing in climbing competitions. Having found a significant increase in injury when climbing intensity scores are higher, the lower incidence of hand and wrist injuries may reflect the lower mean climbing intensity in the Climbers' Club members compared with younger elite climbers.

A tendon injury of the finger was the most common injury type $(33 \%)$. Of all finger, hand, and wrist injuries studied in $13 \%$ of the Danish population, $60 \%$ were wounds, contusions, or abrasions, $9 \%$ were sprains, and $5 \%$ were tendon injuries. ${ }^{8}$ This spectrum of injury is different in climbers, in whom the predominant injury involved the flexor tendons. This is expected, as a series of repetitive high torque movements of the fingers and hands are needed to ascend a wall or rockface.

Many climbers use a number of standard handholds, although other less conventional holds are often applied. Handholds in rock climbing generate large forces in the flexor digitorum profundus and superficialis tendons and the

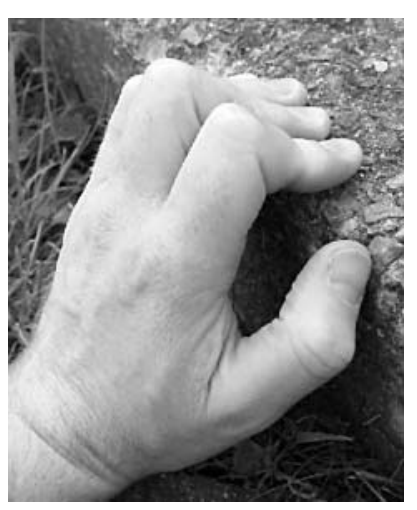

Figure 3 The cling grip.

associated interphalangeal joints. The distribution of forces often depends on the type of hold adopted. This can result in acute rupture or acute episodes of tendonitis. Soft tissue sprains of the wrist accounted for 5\% of the hand injuries in Climbers' Club climbers and was likely to have occurred following repetitive undercling hand holds. ${ }^{2}$

A2 pulley injuries occur most often when the crimp/cling grip is used, especially if associated with a foothold slip suddenly increasing the force on the pulley and causing a rupture. ${ }^{11}$ The middle and ring fingers are most often involved. ${ }^{7}$ During a normal crimp/cling grip (distal interphalangeal joint hyperextended and proximal interphalangeal joints flexed to $90^{\circ}$; fig 3 ), the A2 pulley must sustain $40 \%$ more tension than the tendon. ${ }^{12}$ It has been recommended that the fingers are taped between the joints to reinforce the flexor tendon pulleys while climbing. ${ }^{73}$

Bollen and Gunson ${ }^{9}$ found that $26 \%$ of climbers at a British competition had clinical evidence of a previous A2 pulley rupture, much higher than in the Climbers' Club members ( $2 \%$ of climbers, $8 \%$ of injuries). National competitions only involve elite climbers who train hard for indoor speed climbing and are thus more likely than the average climber to sustain these strain injuries. The proportion of A2 pulley ruptures in the Climbers' Club members is likely to be higher than $8 \%$ of wrist and hand injuries as some of these injuries may not have been specifically diagnosed and therefore were part of the non-specified finger tendon injury group. However, if all non-specific finger tendon injuries were assumed to be undiagnosed A2 pulley ruptures, in Climbers' Club climbers the incidence of A2 pulley rupture would still only be $9 \%$.

The mean climbing intensity scores in the climbers who sustained an acute injury are significantly higher than those in the non-injury group. Despite more experience, the greater intensity score indicates that a climber has spent more time on often more difficult routes. Therefore the longer and harder a climber has climbed, the greater the likelihood of exposure to a situation that may result in injury. This has also been found in a study by Wright et al, ${ }^{6}$ in which climbers were more likely to have been injured if they had climbed for more than 10 years, climbed harder routes, or were the lead climber.

\section{Study limitations}

The limitations of this study are the response rate of $51 \%$, the self diagnosis of some of the injuries, and the time between the injury and completion of the questionnaire.

\section{Response rate}

As the questionnaire was included as a supplement in the Climbers' Club Newsletter, members may not have opened or read it, contributing to the low response rate. It was also 


\section{What is already known}

- Rock climbing injuries are common

- Over half of injuries involve the wrist and hand

therefore not possible to identify and individually contact non-responders. The low response rate may have introduced bias with regard to the overreporting or underreporting of the incidence of injuries. An overreporting bias was less likely as the questionnaire was part of a larger study looking primarily for the presence of Dupuytren's disease in the climbers, and the data on previous hand or wrist injuries were collected in addition. An underreporting bias of wrist and hand injuries is more likely, as the average time interval between age at time of injury and age at completion of the questionnaire was 19 years. Over this time period, climbers may have simply forgotten the occurrence of less severe injuries to the wrist and hand and not reported them.

\section{Self diagnosis of injury}

Most of the tendon and soft tissue injuries reported by the climbers were either diagnosed by themselves or by their general practitioner.

Time interval

Most members join the club around the age of 30 and remain members for life, thus explaining the mean climber age of 50 . The mean time of 19 years between injury and questionnaire gives a historical picture of the incidence of climbing injuries rather than a snapshot of current climbers. Over this time period, there have been considerable advances in the equipment available for climbers, and this is likely to have reduced the number of injuries resulting from falls. As an example, most rope burns resulted from saving a falling colleague. Of the 15 climbers with rope burn, the mean time of injury was 31 years ago (range 14-55). The most recent rope burn in the group of climbers studied occurred 14 years ago. This probably reflects the development of mechanical braking devices which have become available in more recent years. However, it is likely that sprains, tendon, and pulley injuries are more common in the modern climber with the increasing popularity and availability of climbing walls both in and out of season.

\section{What this study adds}

- A detailed study of the pattern of wrist and hand injuries in a large population of dedicated climbers

- The relation between the lifetime intensity of climbing and the likelihood of a wrist or hand injury

\section{CONCLUSIONS}

This study gives a historical picture of the incidence of wrist and hand injuries in club climbers. The greater the climbing intensity calculated over a climber's career, the greater the likelihood of sustaining these injuries, with the predominant type being an injury to the finger tendons or pulleys.

\section{ACKNOWLEDGEMENTS}

We thank the members of The Climbers' Club of Great Britain for the information made available in this study.

\section{Authors' affiliations}

A J Logan, N Makwana, Wrexham Maelor Hospital, Wrexham, Wales, UK

G Mason, Loughborough University, Loughborough, Leics, UK

J Dias, University Hospital Leicester, Leicester, UK

\section{REFERENCES}

1 Bollen SR. Soft tissue injury in extreme rock climbers. Br J Sports Med 1988:22:145-7.

2 Holtzhausen LM, Noakes TD. Elbow, forearm, wrist, and hand injuries among sport rock climbers. Clin J Sport Med 1996;6: 196-203.

3 Rooks MD, Johnston III RB, Ensor CD, et al. Injury patterns in recreational rock climbers. Am J Sport Med 1995;23:683-5.

4 Addiss DG, Baker SP. Mountaineering and rock-climbing injuries in US national parks. Ann Emerg Med 1989;18:975-9.

5 Maitland M. Injuries associated with rock climbing. J Orthop Sports Phys Ther 1992;16:68-72.

6 Wright DM, Royle TJ, Marshall T. Indoor rock climbing: who gets injured? Br J Sports Med 2001;35:181-5.

7 Shea KG, Shea OF, Meals RA. Manual demands and consequences of rock climbing. J Hand Surg [Am] 1992;17:200-5.

8 Angermann $\mathrm{P}$, Lohmann M. Injuries to the hand and wrist. A study of 50272 injuries. J Hand Surg [Br] 1993;18:642-4.

9 Bollen SR, Gunson CK. Hand Injuries in competition climbers. Br I Sport Med 1990;24:16-18.

10 Bollen SR. Upper limb injuries in elite rock climbers. J R Coll Surg Edinb 1990:35:S18-21.

11 Wyatt JP, McNaughton GW, Grant PT. A prospective study of rock climbing injuries. Br J Sports Med 1996;30:148-50.

12 Brand PW. In: Clinical mechanics of the hand. St Louis: Mosby, 1985:30-50.

13 Robinson M. Get a grip on injury prevention and treatment. Climbing 1988:108-13. 